\title{
Experimental analysis of a Vapour-Liquid Separated Flat Loop Heat Pipe Evaporator System
}

\author{
Yang Yang ${ }^{1}$, Zhu Kai ${ }^{2}$, Wang Yabo ${ }^{2}$, Wei Jie ${ }^{3}$ and Sarula Chen ${ }^{1, *}$ \\ ${ }^{1}$ Tianjin University, School of Architecture, 300072 Tianjin, China \\ ${ }^{2}$ Tianjin University of Commerce, Key Laboratory of Refrigeration Technology of Tianjin, 300134 Tianjin, China \\ ${ }^{3}$ Fujitsu LTD, 2118588 Tokyo, Japan
}

\begin{abstract}
In this paper, a unique operation mechanism of loop heat pipe (LHP) was proposed. To test the performance of LHP under this new mechanism, a visual flat LHP evaporator prototype and an open experimental system were designed and assembled, and start-up experiment and variable heat load experiment were done respectively to obtain the actual operation characteristics, such as the evaporator thermal resistance $\left(R_{e}\right)$, total thermal resistance $\left(R_{t}\right)$, start-up time and temperature of base plate. The proposed LHP had better overall performance during the start-up tests when $H_{e}$ value of EC was set to $0.5 \mathrm{~mm}$, and its corresponding $R_{e}$ and $R_{t}$ value were $0.035 \mathrm{~K} / \mathrm{W}$ and $0.451 \mathrm{~K} / \mathrm{W}$ when the heating power was $208 \mathrm{w}$. Meanwhile, as per the heat load applied to the base plate, the whole variable heat load experiment could be divided into three distinct stages: low heat load stage, efficiency operation stage and dry-out stage. Moreover, the results also showed that the circulation driven head formed inside of the EC played an important role in promoting the operation performance, especially when the wick, the vapour-liquid interface and the bottom of the evaporator arrived at a reasonable situation.
\end{abstract}

\section{Introduction}

It is known that the cooling device is critical to promote high heat flux components' operation reliability, performance improvement and lifespan extension [1, 2]. Lots of previous studies have shown that the development speed and scale of large application servers and data centers will largely be affected by the research and development progress of its cooling devices [3-5]. With the rapid development of related industries, such as large application servers, data processing centers and aerospace equipment, the demand for more costeffective thermal management has become more and more urgent than ever before.

After the first flat loop heat pipe (FLHP) was put forwarded by Yu. F. Gerasimov in 1975[6], this type of LHP has aroused worldwide interests due to its various advantages compared to other traditional cooling devices. And targeted researches to FLHP have been carried out all over the world, including structural optimization of LHP [7, 8], heat and mass transfer process studies in the internal of LHP $[9,10]$, wick selection and fabrication [11-14], working medium selection and charging principle [15], performance and reliability study [16-18], etc. In recent years, FLHP has played an irreplaceable role in the cooling field of high heat flux components [19]. Therefore, how to improve the running performance of FLHP has become the research focus of many scholars within this field [20, 21]. Currently, more and more scholars deem that the capillary wick, one of the most important components of LHP, is the key factor which influence and determine the capillary absorption rate during the heat transfer process. And much of the related studies have revolved around the performance parameters of capillary wick, such as the thermal conductivity, porosity, permeability and capillary radius of the wick, charge ratio, heat load and backflow angle $[22,23]$.

In fact, the operation theory of LHP is to utilize vapour pressure head and the liquid pressure head which generated at the phase change interface within the wick to drive the continues circulation of working fluid, and then remove the heat in base plate efficiency through evaporation and condensing [24]. Usually, different working fluids, surface shapes and heat source dimensions, i.e. flat or cylindrical evaporator, would be chosen for different application purpose. Since the surface shape of most heat source are flat, the flat type evaporator has been used more widely than cylindrical evaporators. For a FLHP, the evaporator usually is designed to be a sealed chamber, and the capillary wick would be installed in of the chamber. And a condenser is indispensable and must be connected to the evaporator by two separate pipes to form a closed cycle.

However, this kind of design and operation mechanism of traditional LHP above usually leads to the greater flow resistance inside of the LHP, letting heat transfer efficiency limits become an inevitable problem [25, 26]. Actually, the capillary wick inside of this type LHP plays a vital function in driving working fluid at

\footnotetext{
* Corresponding author: sarul@,tju.edu.cn
} 
condenser back to evaporation to maintain the operation cycle, while the driving force is mainly generated at the location of phase change interface in the pore of capillary wick [27]. Therefore, the main features and common problems faced by capillary phase change mechanism are: (1) two-phase flow will generate in the LHP due to the vapour-liquid interface existing in the wick during operation; (2) the parasitic heat leak in the evaporator increases its circulation flow resistance [2830]. The inevitable problems above have extremely negative impacts on the further application.

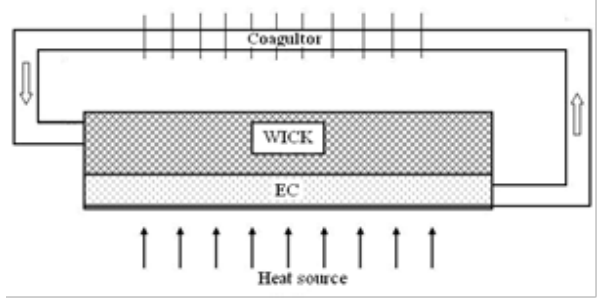

Fig. 1. Schematic diagram of LHP driven by phase change force.

In this paper, a flat loop heat pipe mainly driven by the phase change generated at the vapour-liquid interface inside of EC was proposed, as shown in Fig. 1. After the re-design, the working fluid inside of the proposed LHP could only do one-way circulation. Compared with traditional FLHP, an additional phase change space was placed between the capillary wick and base plate to remove the vapour-liquid interface from wick, which was called the evaporation chamber (EC). As such, this distinction leads to the main difference on heat transfer mechanism between traditional LHP and the proposed LHP. Since the vapour-liquid interface was not inside of the wick any more, the proposed LHP utilizes the vapour generated in the EC to drive working fluid to complete the circulation instead of the phase change formed at the interface in the pore of capillary wick. The region between capillary wick and the base plate plays a part in preventing the generation of boiling phenomenon in the wick, so the shear flow resistance caused by the phase change and the partial pressure of vapour in the wick was near to zero. Therefore, the flow resistance would then be reduced under the same seepage pressure in the wick. At the outlet of the vapour chamber, a buffer space, namely, the pressure sharing chamber, was designed to maintain the working medium in the vapour chamber realizing unidirectional phase of liquid to vapour to avoid the phase change phenomenon in the wick.

To avoid the occurrence of boiling phenomenon in capillary wick, the sub-cooling degree of back flow and $H_{e}$ value of EC shall be controlled at a reasonable value. In addition, a wick with low thermal conductivity and suitable porosity is critical in the evaporator as well. This LHP evaporator design method could effectively guarantee that no or only little reverse flow would formed inside the capillary wick and therefore the flow resistance of vapour to the outlet was much less than the flow resistance of vapour to the wick. Through this design, the heat load applied to the base plate could mainly be taken away by evaporation within the EC, thus achieving the purpose of reducing heat leak.

An excellent LHP is contributed by the good start-up and operational performance. In this paper, a unique operation mechanism of loop heat pipe (LHP) introduced above is proposed to enhance the heat application effect of LHP and start-up experiment and variable heat load experiment were done respectively to obtain the actual operation characteristics, such as $R_{e}, R_{t}$, start-up time and temperature of base plate.

\section{Experimental methodology}

\subsection{Experiment apparatus}

In this paper, an evaporator with visualization structure was designed to observe heat and mass transfer process, which had a vital impact on the real thermal control characteristics of LHP. As depicted in Fig. 2, the whole experiment system consisted of computer (1), data acquisition system (2), DC regulated power supply (3), water supply system (4), open-type visualization LHP evaporator (5), simulated heat source (6) and cold water tank (7). For the evaporator, it was assembled by capillary wick, evaporation chamber (EC) which was under the capillary wick, pressure-balance chamber $(\mathrm{PbC})$ which located at the outlet of evaporator, compensation chamber (CC) which was above the capillary wick, vapour removal outlet and the liquid supply inlet.

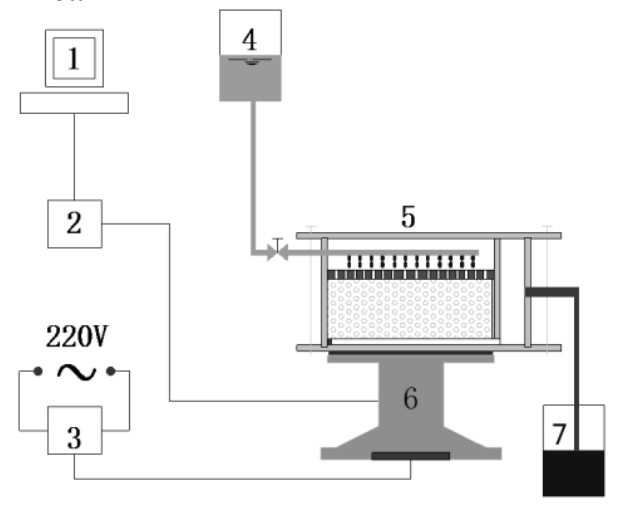

Fig. 2. Schematic of experimental prototype.

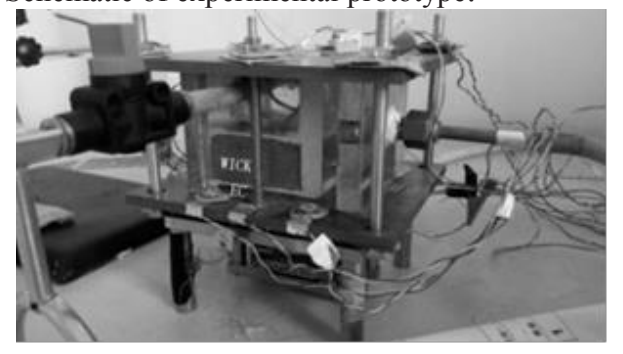

Fig. 3. Schematic of the visualization LHP.

To get a clear observation and explore its operation mechanism inside of the evaporator during its operation process, the evaporator envelop was made of four $10 \mathrm{~mm}$ transparent quartz glasses. The top plate and base plate of the evaporator were in shape of rectangular and was made of brass material, while the design dimension was $130 \mathrm{~mm}(L) \times 110 \mathrm{~mm}(W)$. Meanwhile, the dimension 
of the thermal contact face of simulated heat source which connected with base plate was $75 \mathrm{~mm}(L) \times 50$ $\mathrm{mm}(W)$. To reduce the heat leak to compensation chamber through heat conduction of capillary wick, a 20 -mm thickness molecular sieve (porosity 40\%) which had a low thermal conductivity was used as the wick. To simulate the CPU heating process, a silicon heating plate of $25 \mathrm{~mm}(L) \times 25 \mathrm{~mm}(W) \times 2 \mathrm{~mm}(H)$ was placed at the bottom of the I-type copper block, and the heating power was adjusted by DC power supply. In addition, to reduce the thermal contact resistance, the carbon fiber film with thermal conductivity of $75 \mathrm{~W} / \mathrm{m} \cdot \mathrm{K}$ was placed between the base plate of evaporator and copper block. Finally, the evaporator was bolted together with four bolts, as depicted in Fig. 3.

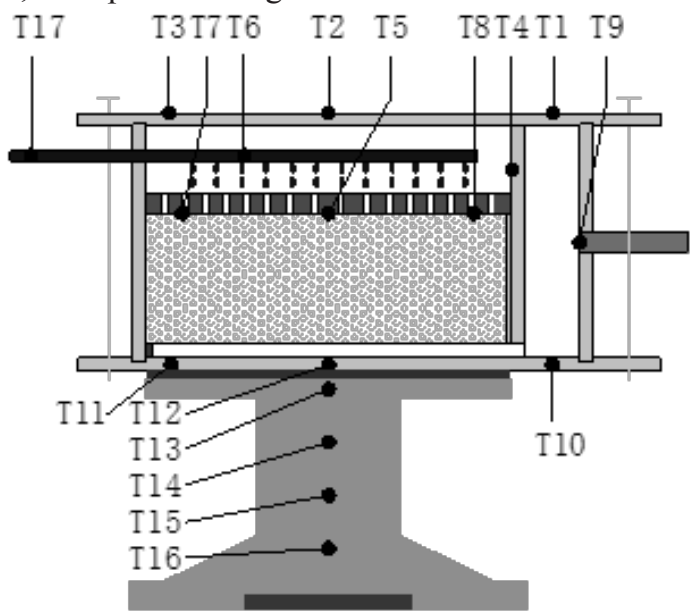

Fig. 4. Test layout of the evaporator.

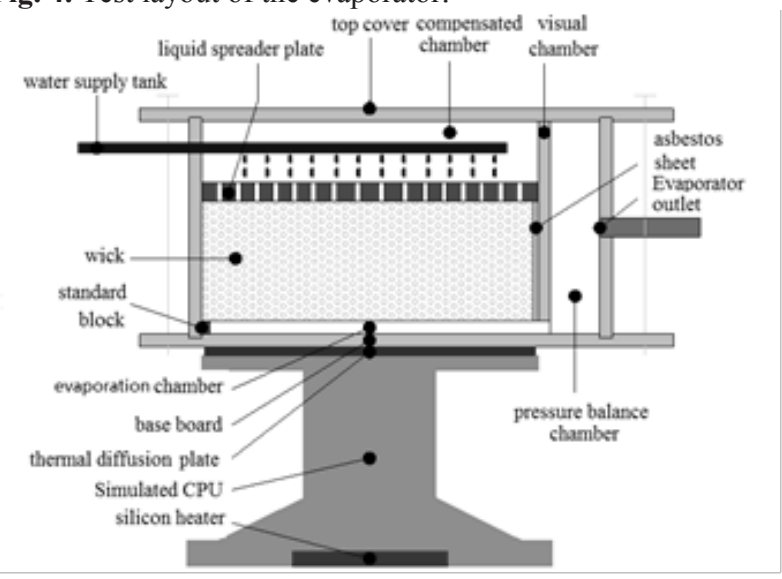

Fig. 5. Cross-sectional details of the evaporator.

At the same time, Yokogawa GP10 Data Acquisition System was adopted to record temperature data with eighteen T-type thermocouples (Copper-constantan Thermocouples). Detailed measuring points location and cross-section structure of the proposed evaporator were showed in Fig. 4 and Fig. 5, respectively. $T_{1}-T_{3}$ were placed at the top plate for temperature measurement. $T_{4}$ was used to measure the temperature above the wick. $T_{5}$ $T_{7}$ were placed at the upper wick to monitor the temperature changes. $T_{6}$ was used for measuring the supply water temperature and $T_{17}$ was used for measuring the water temperature in the water supply tank. $T_{9}$ was used to monitor the vapour temperature at the evaporator outlet. $T_{10}-T_{12}$ were inserted into the base plate to measure the wall temperature. $T_{13}-T_{16}$ were inserted into the copper block to calculate the real time heating power. Besides, another thermocouple was used to measure ambient temperature during the experiment. It should be clear that the accuracy of $T_{1}-T_{12}, T_{17}-T_{18}(0.2$ $\mathrm{mm}$ diameter $)$ and $T_{13}-T_{16}(0.1 \mathrm{~mm}$ diameter $)$ were \pm 0.2 ${ }^{\circ} \mathrm{C}$.

\subsection{Test procedures}

Before the tests, distilled water was charged into the liquid tank to avoid the experiments being influenced by impurities [31]. Except for the liquid tank and the vapour cooling tank, all components were placed at the test bench horizontally during the test. The liquid tank was placed above the evaporator, and the vapour cooling tank was placed below the evaporator. After tests begin, all monitoring temperature would be auto-recorded in Yokogawa GP10.

This paper mainly focuses on the heat and mass transfer process inside of the evaporator, so an open experimental system was deliberately designed. Therefore, observation of stable vapour generated inside of the EC during the start-up process shall be the complete start-up judgment criterion. The evaporator start-up test was conducted under different $H_{e}$ value of $\mathrm{EC}$, including $0.5,1,3$ and $5 \mathrm{~mm}$. Before the test beginning, the same initial liquid level inside of the EC was set to $1 \mathrm{~mm}$ to simulate the actual distribution of water under the influence of gravity.

\section{Data processing}

It is known that the safe running of high heat flux equipment is usually depend on the successful start-up of LHP directly. Thus, in this paper the experiment studies about the start-up and variable heat load process are of vital importance to the future application of the proposed LHP, including the start-up time, base plate temperature and the thermal resistance. Generally, $R_{e}$ and $R_{t}$ value are important parameters that reflect the performance of LHP during the operation [16, 32, 33]; those two thermal resistances are defined as:

$$
\begin{gathered}
R_{\mathrm{e}}=\left(T_{\mathrm{e}}-T_{\mathrm{v}}\right) / \mathrm{Q} \\
R_{\text {total }}=\left(T_{\mathrm{j}}-T_{\mathrm{a}}\right) / \mathrm{Q}
\end{gathered}
$$

Where $Q$ is the heating power applied to the base plate, and real time value of $Q$ is obtained by calculating $T_{13^{-}}$ $T_{16}$ in the copper block; $T_{e}$ is the average temperature of $T_{10}-T_{12} ; T_{v}$ is the vapour temperature at the evaporator outlet $\left(\mathrm{T}_{9}\right) ; T_{j}$ is the actual temperature in the middle of simulated CPU surface $\left(T_{12}\right)$; Ta is the ambient temperature.

\section{Results and discussion}

\subsection{Evaporator start-up experiment}


Fig.6 and Fig.7 respectively show the start-up time and base plate temperature varying with other operation parameters, such as the height of EC and heating power. As can be seen from Fig.6, under the same evaporation chamber height $\left(H_{e}\right)$, the greater that of the heating power applied to the bottom plate, the less time that of the start-up process required. Furthermore, the start-up process cannot be established whatever the He value is when heating power is less than a certain value. Besides, the greater $H_{e}$ value requires less start-up time at the same heating power.

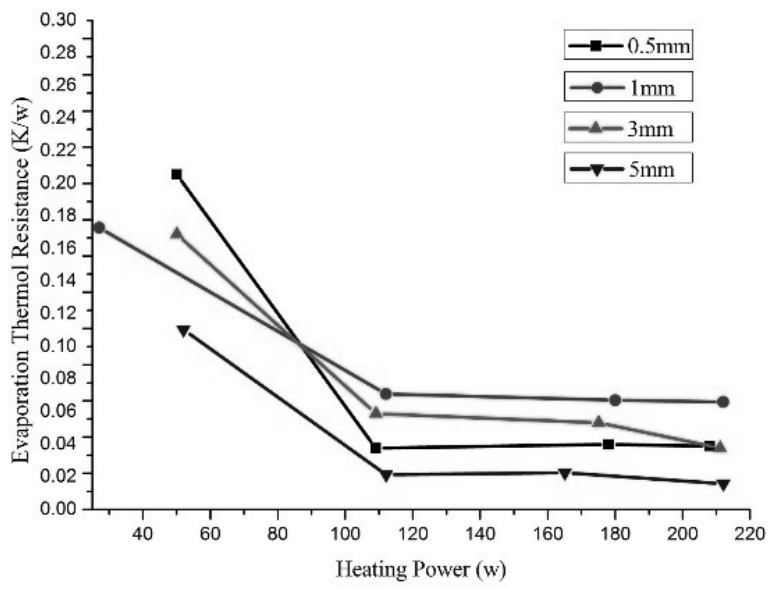

Fig. 6. Influence of $H_{e}$ value on $R e$.

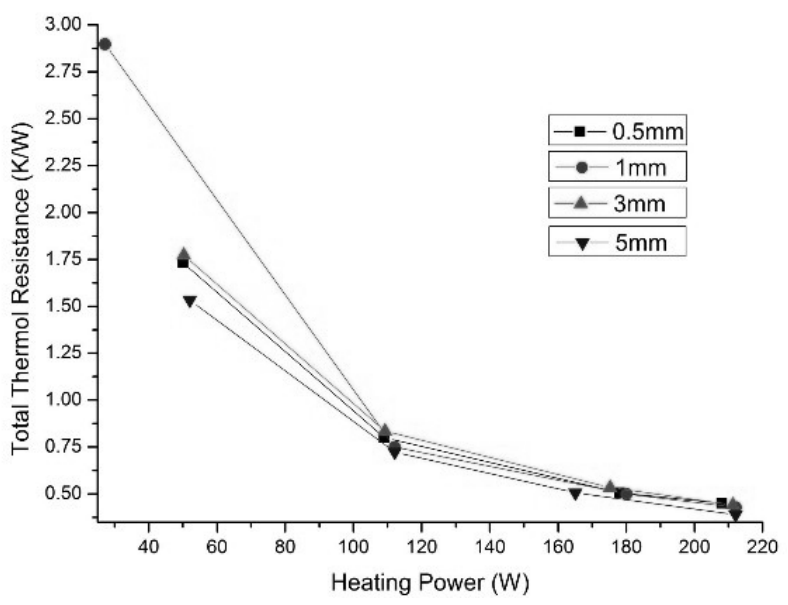

Fig. 7. Influence of $H_{e}$ value on $R_{t}$.

Actually, the reason why it's not easy to build the cycle at smaller heating power condition is that the vapour produced inside the EC has already been cooled down in $\mathrm{EC}$ and $\mathrm{PbC}$ and return to $\mathrm{EC}$ before entering the vapour pipe, and therefore it cannot generate enough pressure difference in the $\mathrm{EC}$ and $\mathrm{PbC}$ to drive the circulation of working fluid. By contrast, large amounts of vapour created by high heating power can produce enough pressure difference between evaporator and condensing unit to discharge the generated vapour in time, and drive liquid working fluid to the compensation chamber, thus full circulation in LHP is established. Besides, the phenomenon that the higher $H_{e}$ value leads to the less start-up time can be explained by taking $1 \mathrm{~mm}$ and $5 \mathrm{~mm}$ condition as examples. Under $1 \mathrm{~mm}$ condition, the wick contact directly with the initial liquid level of working fluid, thus partially heat flux excluding the heat conduction loss caused by the envelop is passed to the wick through the heat conduction and the heat flux absorbed directly by the working fluid is correspondingly reduced, thus leading to the longer startup time. However, under higher $H_{e}$ value condition like $5 \mathrm{~mm}$, there is still a space between the wick and initial interface of liquid working fluid in EC, and due to the lack of direct contact, there is almost no heat leakage happened and most of the heat flux is directly absorbed by the working fluid except for partially loss caused by the radiation heat transfer between the wick and working fluid in EC and heat conduction loss caused by the envelop, thus leading to the shorter start-up time.

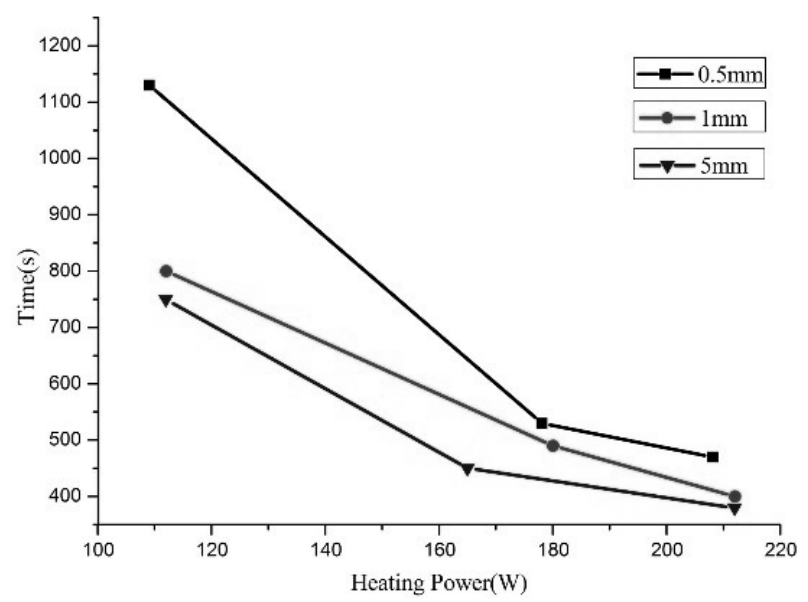

Fig. 8. Influence of $H_{e}$ value on start-up time.

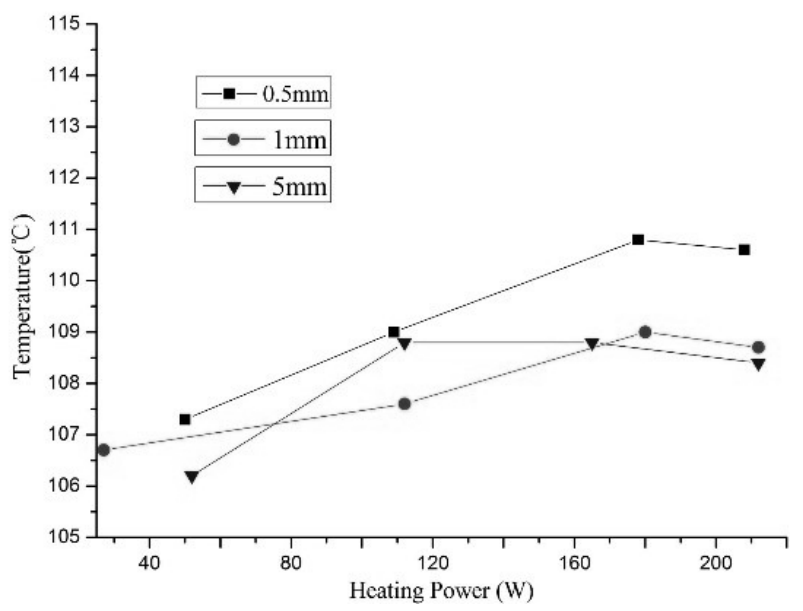

Fig. 9. Influence of $H_{e}$ value on base plate temperature.

Fig. 8 and Fig.9 show how $R_{e}$ and $R_{t}$ changes with different evaporation chamber height $\left(H_{e}\right)$, i.e. $0.5 \mathrm{~mm}, 1$ $\mathrm{mm}, 3 \mathrm{~mm}$ and $5 \mathrm{~mm}$, respectively during start-up process. The results in Fig. 1 shows that the $R_{e}$ values decrease gradually with the rising heating power when $H_{e}$ value remains at a certain value, and the $R_{e}$ values calculated at the higher $H_{e}$ and lower $H_{e}$ condition i.e. 5 and $0.5 \mathrm{~mm}$ are smaller than the values obtained at middle $H_{e}$ condition, i.e. 1 and $3 \mathrm{~mm}$. The results in Fig.9 shows that the $R_{t}$ values decrease gradually with the heating power increase at the same $H_{e}$ condition. Meanwhile, it should be noted that the difference of $R_{t}$ value that obtained at different $H_{e}$ conditions also decrease with the increasing of heating power. These phenomenon can be attributed to the following reasons. 
On the one hand, before the steady cycle is established, the whole evaporator is equivalent to a heat conductor, therefore the evaporator itself can be cooled only by means of natural convection and radiation with its surroundings, causing higher $R_{e}$ and $R_{t}$ values in this stage. On the other hand, after the steady cycle is established, the $R_{e}$ and $R_{t}$ values will decrease to a lower value rapidly. And at the same time, a higher $H_{e}$ value in LHP evaporator is more favourable to discharge the produced steam than smaller $H_{e}$ value situation, thus improving the boiling efficiency and causing a sharp decrease of the $R_{e}$ and the $R_{t}$ of LHP.

Based on the analysis above, some meaningful results could be obtained. Firstly, the evaporation efficiency of working fluid in EC has a vital influence on the evaporator performance while the $H_{e}$ value of EC has a significant influence on the evaporation efficiency of working fluid in EC and the cycle stability. Though a larger $H_{e}$ value, which means a larger evaporation phase change space, is helpful for reducing the thermal resistance, however it also lead to appearance of dry out phenomenon inside of the evaporator. Furthermore, the smaller $H_{e}$ value not only can achieve a relative smaller value of thermal resistance, but also is useful for miniaturization of system LHP. Therefore, from the point of view, the EC design parameter, i.e. $H_{e}$ value, set to $0.5 \mathrm{~mm}$ has a better performance than others in this paper. The minimum $R_{e}$ and $R_{t}$ under $0.5 \mathrm{~mm} \mathrm{EC}$ condition is $0.035 \mathrm{~K} / \mathrm{W}$ and $0.451 \mathrm{~K} / \mathrm{W}$ when the heating power is $208 \mathrm{~W}$.

\subsection{Variable heat load experiment}

During the variable heat load tests, the initial heating power of the $1 \mathrm{~mm}$ EC condition was $10 \mathrm{~W}$, and then the heating power was gradually increased at the rate of 10 $\mathrm{W}$ each adjustment. To reduce the experimental time in the following tests, i.e. $0.5 \mathrm{~mm}, 3 \mathrm{~mm}$ and $5 \mathrm{~mm}$, the initial heating power was set to $20 \mathrm{~W}$ and increased at the rate of $20 \mathrm{~W}$ each adjustment. Fig. 10a to Fig. 10d and Fig. 11a to Fig. 11d respectively show the variation curve of $R_{e}$ and $R_{t}$ under $0.5,1,3$ and 5mm condition. As can be seen from the Fig. 10 and Fig. 11, especially Fig. $10 \mathrm{~d}$ and Fig. $11 \mathrm{~d}$, as per the variation trend of the $R_{e}$ and $R_{t}$, the variable heat load test process could also be divided into three stages: low heat load stage, efficiency operation stage and dry-out stage.

Taking $5 \mathrm{~mm}$ He value condition for further analysis, the evaporator continued worked in the scope low heat load stage when the heating power less than $70 \mathrm{~W}(2.31$ $\mathrm{W} / \mathrm{cm}^{2}$ ). That was due to the steady circulation inside of evaporator had not been established, the evaporator was in the process of heat storage and the superheat degree between the bottom plate and the saturation temperature of working fluid could not reach to the required value, therefore the heat load applied to the base plate could not be removed efficiently, resulting in the higher $R_{e}$ and $R_{t}$ value. As the heating power raised continually, though some vapour bubbles appeared in the EC during the test, this boiling process actually belonged to "sub-cooled boiling". During this period, the vapour re-condensated inside of the $\mathrm{EC}$ and $\mathrm{PbC}$ and then flow back to the bottom plate, resulting in the drastic vapour temperature fluctuation phenomenon at the evaporator outlet. When
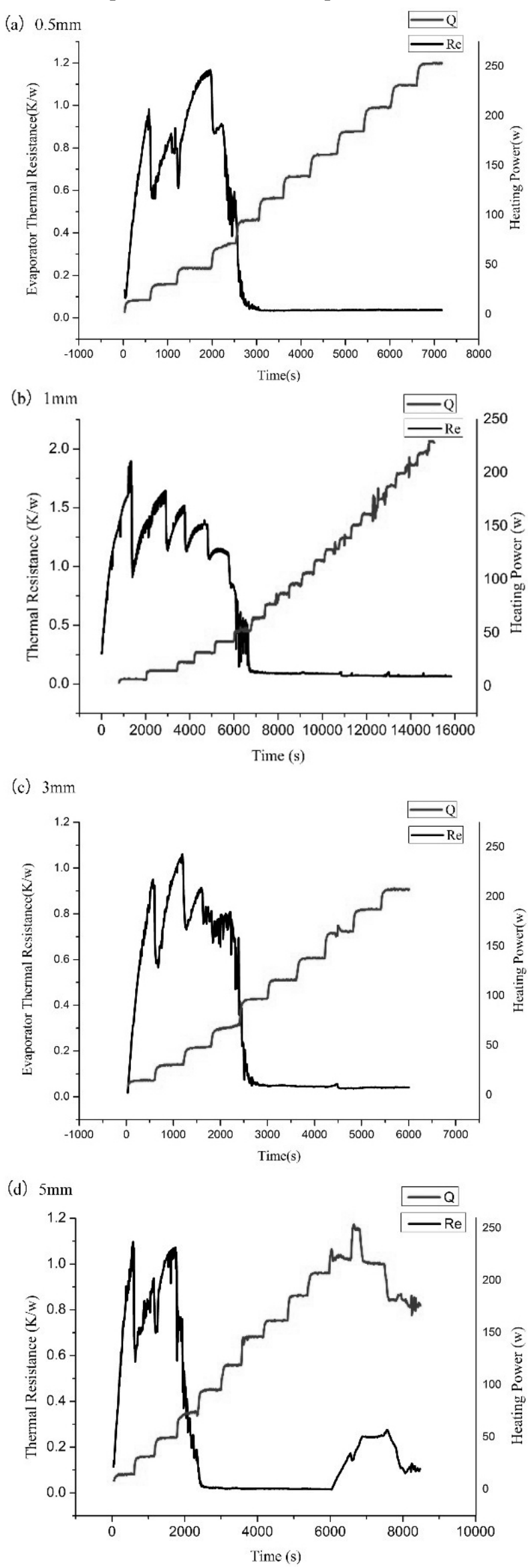
Fig. 10. $R_{e}$ value variation during variable heat load experiment at different $H_{e}$ value.

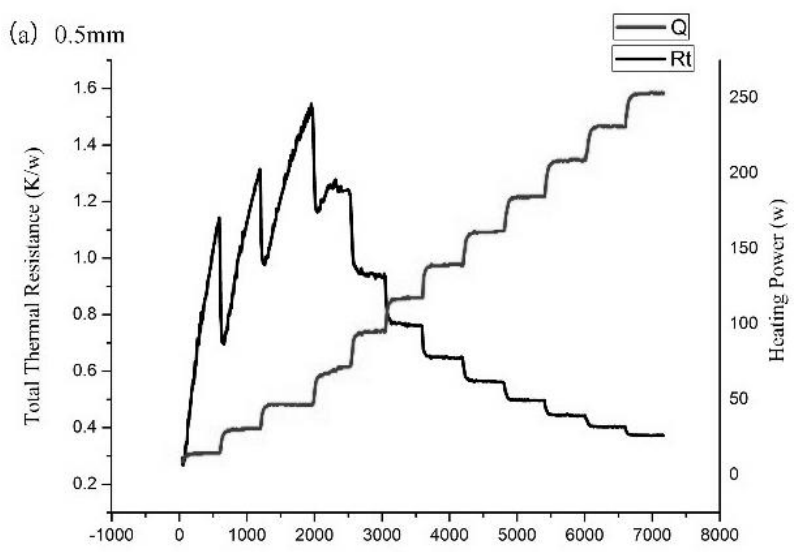

(b) $1 \mathrm{~mm}$
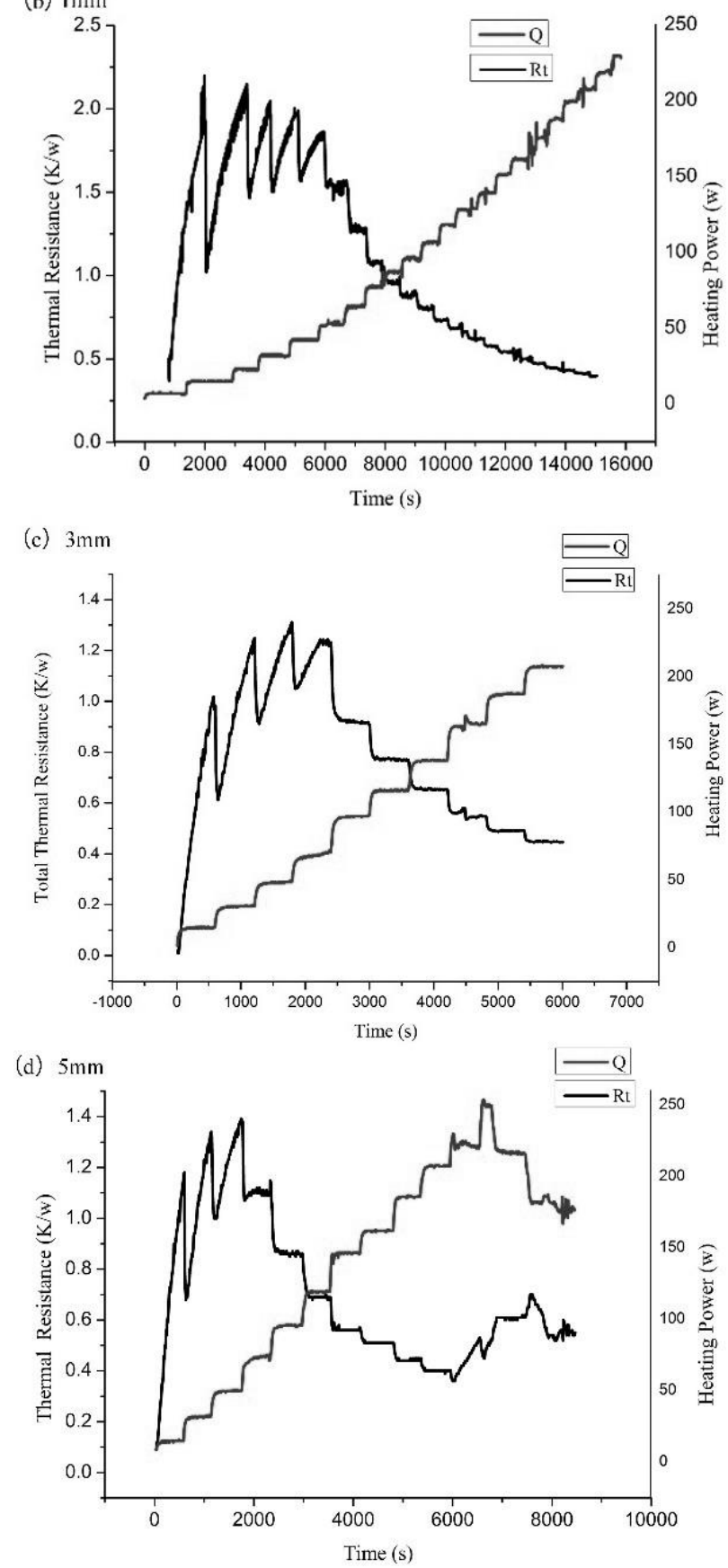

Fig. 11. $R_{t}$ value variation during variable heat load experiment at different $H_{e}$ value.

heating power exceeded $70 \mathrm{~W}$ but not exceeded $210 \mathrm{~W}$, the bottom plate temperature would rise further, thus the superheat degree would also rise further. Then, stabilization boiling formed inside of EC, and most of the heat load applied to the bottom plate could be taken away through phase change heat transfer, thus $R_{e}$ and $R_{t}$ value decreased rapidly in this stage. Meanwhile, the bottom plate temperature tended to be stable and finally was under effective control despite the increase of heating power. When heating power exceeded $210 \mathrm{~W}$, the bottom plate temperature raised rapidly and the working fluid could not be compensated in time from the wick above, finally the $R_{e}$ and $R_{t}$ value could not remain at lower level and thus dry-out phenomenon appeared inside the evaporator at this time.

Finally, the results of variable heat load test show that the minimum $R_{e}$ of different $H_{e}$ value condition was $0.036 \mathrm{~K} / \mathrm{W}(0.5 \mathrm{~mm}), 0.065 \mathrm{~K} / \mathrm{w}(1 \mathrm{~mm}), 0.041 \mathrm{~K} / \mathrm{W}(3$ $\mathrm{mm})$ and $0.016 \mathrm{~K} / \mathrm{W} \quad(5 \mathrm{~mm})$, meanwhile the corresponding minimum $R_{t}$ of different $H_{e}$ value condition was $0.405 \mathrm{~K} / \mathrm{W}(0.5 \mathrm{~mm}), 0.413 \mathrm{~K} / \mathrm{W}(1 \mathrm{~mm})$, $0.406 \mathrm{~K} / \mathrm{W}(3 \mathrm{~mm})$ and $0.398 \mathrm{~K} / \mathrm{W}(5 \mathrm{~mm})$. Besides, some other meaningful results could be obtained from the variable heat load test above: No dry-out phenomenon was observed in the EC within the heating range of the test when $\mathrm{EC}$ height was less than $5 \mathrm{~mm}$, and there was a heating limit when the $\mathrm{EC}$ was $5 \mathrm{~mm}$. In other words, a higher EC height was beneficial to reduce the thermal resistance, and a smaller EC height could help avoid the happening of dry-out phenomenon in the evaporator.

\section{Conclusions}

This paper focused on a visualization evaporator of FLHP with special structure in which there is no contact between base plate and capillary wick, i.e., the vapourliquid interface was separated from the capillary wick directly. This type of LHP was mainly driven by the phase change generated inside of the EC to complete the single direction circulation. This paper mainly focused on the analysis relationship between design parameters, such as the $H_{e}$ value, heating power, and the performance parameters, such as the $R_{e}$ value, $R_{t}$ value, start-up time and base plate temperature during start-up and variable heat load experiments. The following conclusions could be drawn:

1. Start-up experiments showed that working fluid evaporation efficiency in EC has a vital influence on the evaporator performance while the $\mathrm{He}$ value of $\mathrm{EC}$ has a significant influence on the evaporation efficiency and the cycle stability. The evaporator has a better performance when $H_{e}$ value of EC was set to $0.5 \mathrm{~mm}$ and the corresponding minimum $R_{e}$ and $R_{t}$ is $0.035 \mathrm{~K} / \mathrm{W}$ and $0.451 \mathrm{~K} / \mathrm{W}$ when the heating power is $208 \mathrm{~W}$.

2. Variable heat load experiment showed that a higher EC height was beneficial to reduce the thermal resistance, and a smaller EC height could help prevent the happening of dry-out phenomenon in the evaporator. 
the results of variable heat load test show that the minimum $R_{e}$ of different $H_{e}$ value condition was 0.036 $\mathrm{K} / \mathrm{W}(0.5 \mathrm{~mm}), 0.065 \mathrm{~K} / \mathrm{W}(1 \mathrm{~mm}), 0.041 \mathrm{~K} / \mathrm{W}(3 \mathrm{~mm})$ and $0.016 \mathrm{~K} / \mathrm{w}(5 \mathrm{~mm})$, meanwhile the corresponding minimum $R_{t}$ of different $H_{e}$ value condition was 0.405 $\mathrm{K} / \mathrm{W}(0.5 \mathrm{~mm}), 0.413 \mathrm{~K} / \mathrm{W}(1 \mathrm{~mm}), 0.406 \mathrm{~K} / \mathrm{W}(3 \mathrm{~mm})$ and $0.398 \mathrm{~K} / \mathrm{W}(5 \mathrm{~mm})$.

3. As per the change curve of thermal resistance, the variable heat load experiment process can also be divided into three stages: low heat load stage, high efficient cycle stage and dry-out stage. A dry-out phenomenon appears in the $5 \mathrm{~mm}$ height condition when heat load is increased to $220 \mathrm{~W}$ and the vapour-liquid interface appears in the wick. However, the same phenomenon does not appear in the $1 \mathrm{~mm}$ height condition, i.e. a smaller EC is beneficial to restrain the generation of dry-out.

4. The new operation mechanism that the LHP is driven by the phase change generated at of the EC is feasible and effective through the experiment. And it was built on the premises that the $H_{e}$ value of EC and sub-cooling degree of condensate should be controlled at a certain range, these measure can therefore effectively increase the seepage force in the capillary wick and maintain a sufficient driven force in evaporator.

This study is supported by National Science Foundation of China (No. 51376137) and Science Foundation of Tianjin (No. 13JCZDJC27300).

\section{References}

1. Maydanik Y F, Pastukhov V G, Chernysheva M A. Development and Investigation of a Miniature Copper-Acetone Loop Heat Pipe with a Flat Evapourator [J]. Journal of Electronics Cooling \& Thermal Control, 2015, 05(4):77-88.

2. Yang $\mathrm{Y}, \mathrm{Zhu} \mathrm{K}$, Wang $\mathrm{Y}$, et al. Experimental investigation and visual observation of a vapourliquid separated flat loop heat pipe evapourator $[\mathrm{J}]$. Applied Thermal Engineering, 2016, 101:71-78.

3. Singh R, Nguyen T, Mochizuki M. Capillary evapourator development and qualification for loop heat pipes[J]. Applied Thermal Engineering, 2014, 63(1):406-418.

4. Vasiliev, L, Lossouarn, D., Romestant, C., et al. Loop heat pipe for cooling of high-power electronic components, International Journal of Heat and Mass Transfer (2008), Volume 52, Issues 1-2, 15 January 2009, pp.301-308

5. Liu Z, Wang D, Jiang C, et al. Experimental study on loop heat pipe with two-wick flat evapourator[J]. International Journal of Thermal Sciences, 2015, 94:9-17.

6. Yu.F. Gerasimov, Yu.F. Maydanik, V.M. Kiseev, et al. Evapouration Chamber of a Heat Pipe, USSR Inventor Certificate 495522, 1975.

7. Kiseev V M, Vlassov V V, Muraoka I. Experimental optimization of capillary structures for loop heat pipes and heat switches [J]. Applied Thermal Engineering, 2010, 30(11): 1312-1319.
8. Crepinsek M, Park C. Experimental analysis of pump-assisted and capillary-driven dualevapourators two-phase cooling loop [J].Applied Thermal Engineering, 2012, 38: 133-142.

9. Ren $\mathrm{C}, \mathrm{Wu} \mathrm{Q} \mathrm{S}, \mathrm{Hu} \mathrm{M}$ B. Heat transfer with flow and evapouration in loop heat pipe's wick at low or moderate heat fluxes $[\mathrm{J}]$. International Journal of Heat and Mass Transfer, 2007, 50(11): 2296-2308.

10. Siedel B, Sartre V, Lefèvre F. Numerical investigation of the thermo-hydraulic behavior of a complete loop heat pipe [J].Applied Thermal Engineering, 2013, 61(2): 541-553.

11. Yeh C C, Liu B H, Chen Y M. A study of loop heat pipe with bi-porous wicks [J]. Heat and Mass Transfer, 2008, 44(12): 1537-1547.

12. Boo J H, Chung W B. Experimental study on the thermal performance of a small-scale loop heat pipe with polypropylene wick [J]. Journal of mechanical science and technology, 2005, 19(4): 1052-1061.

13. Liu Z, Gai D, Li H, et al. Investigation of impact of different working fluids on the operational characteristics of miniature LHP with flat evapourator[J]. Applied Thermal Engineering, 2011, 31(16): 3387-3392.

14. Joung W, Yu T, Lee J. Experimental study on the loop heat pipe with a planar bifacial wick structure $[\mathrm{J}]$. International Journal of Heat and Mass Transfer, 2008, 51(7): 1573-1581.

15. V. M. Kiseev, A. S. Nepomnyashy, N.L. Gruzdova, K.S. Kim. Miniature loop heatpipes for CPU cooling, in: Proceedings of the 7th International Heat Pipe Symposium, Jeju, Korea, 2003, pp. $175 \mathrm{e} 180$.

16. Singh R, Akbarzadeh A, Mochizuki M. Operational characteristics of a miniature loop heat pipe with flat evapourator [J]. International Journal of Thermal Sciences, 2008, 47(11): 1504-1515.

17. Li J, Wang D, Peterson G P. Experimental studies on a high performance compact loop heat pipe with a square flat evapourator[J]. Applied Thermal Engineering, 2010, 30(6): 741-752.

18. Wang S, Zhang W, Zhang X, et al. Study on start-up characteristics of loop heat pipe under low-power [J]. International Journal of Heat and Mass Transfer, 2011, 54(4): 1002-1007.

19. Deeney, J. "Thermal Modeling and Measurement of High Power Silicon Devices with Asymmetric Power Distribution," Proc of 35th IMAPS International Symposium on Microelectronics, 2002

20. Prasher R. A Simplified Conduction Based Modeling Scheme for Design Sensitivity Study of Thermal Solution Utilizing Heat Pipe and Vapour Chamber Technology [J]. Electronic Packaging, Vol. 125, pp. 378-385, 2003

21. Xu, G., Follmer, L., Cooley J., et al. Thermal solution development for the Sun FireTM E25K server, Proceedings of SEMI-THERM21 (2005), San Jose, USA 
22. Randeep Singh, Thang Nguyen, Masataka Mochizuki. Capillary evapourator development and qualification for loop heat pipes [J]. Applied Thermal Engineering. 2014. 63(1): 406-418

23. S. Becker, S. Vershinin, V. Sartreet al. Steady state operation of a copper-water LHP with a flat-oval evapourator[J]. Applied Thermal Engineering. 2011. 31(5): 686-695

24. Maydanik Y F, Chernysheva M A, Pastukhov V G. Review: Loop heat pipes with flat evapourators [J].Applied Thermal Engineering, 2014, 67(1): 294307.

25. J. Ku, D. M. Douglas, Michael Pauken, Miniature Loop Heat Pipe with Multiple Evapourators for Thermal Control of Small Spacecraft, N.G.S.F. Center, Editor. 2004

26. H. Nagano, J. Ku, Capillary limit of a multipleevapourator and multiple-condenser miniature loop heat pipe [J]. Journal of Thermo-physics and Heat Transfer, 2007. 21(4), pp. 694

27. Yu.F. Gerasimov, Yu.F. Maydanik, G.T. Shchogolev, et.al. Low-temperature heat pipes with separate channels for vapour and liquid, Eng.-Phys. J. 28 (6) (1975) 957-960 (in Russian).

28. Singh R, Nguyen T, Mochizuki M. Capillary evapourator development and qualification for loop heat pipes [J]. Applied Thermal Engineering, 2014, 63(1): 406-418.

29. X.H. Nguyen, B.H. Sung, J. Choi, et al. Study on heat transfer performance for loop heat pipe with circular flat evapourator, Int. J. Heat Mass Transfer 55 (4) (2012) 1304e1315.

30. Xu J, Zhang L, Xu H. Performance of LHPs with a novel design evapourator $[\mathrm{J}]$. International Journal of Heat and Mass Transfer, 2012, 55(23): 70057014.

31. Xu J, Zhang L, Xu H. Experimental investigation and visual observation of loop heat pipes with twolayer composite wicks [J]. International Journal of Heat and Mass Transfer, 2014, 72: 378-387

32. Singh R, Akbarzadeh A, Mochizuki M. Operational characteristics of a miniature loop heat pipe with flat evapourator [J]. International Journal of Thermal Sciences, 2008, 47(11): 1504-1515.

33. Singh R, Akbarzadeh A, Dixon C, et al. Novel design of a miniature loop heat pipe evapourator for electronic cooling $[\mathrm{J}]$. Journal of Heat Transfer, 2007, 129(10): 1445-1452 